\title{
Development of Competency of Instruction Quality Scale and Evaluation of Practicum Scale ${ }^{*}$
}

\author{
Güntay Taşçi \\ Erzincan University, Erzincan, Turkey
}

\author{
Zafer Çepni \\ Hacettepe University, Ankara, Turkey
}

\begin{abstract}
The aim of this study is to develop data collection tools for evaluation of school practice courses and for perceptions of teacher candidates regarding teacher competencies for effective teaching. Three hundred and eighty-eight last year undergraduate students from seven programs of faculties of education at two state universities participated in the study. Items of the 5-point Likert scale were written according to the dimensions of the constructs with respect to the related literature. The items were reviewed by three experts, one of whom is in the educational measurement and two of whom are in the science and biology education departments. Dimensionalities of the two-dimensional Evaluation of Practicum Scale (EPS) and one-dimensional Competency of Instruction Quality Scale (CIQS) were analyzed using factor analysis. Unweighted least squares estimation method and Promax rotation were used in the factor analysis procedures. Cronbach's $\alpha$ coefficients were 0.89 and 0.83 for the two dimensions of EPS and 0.82 for CIQS.
\end{abstract}

Keywords: teaching quality, teacher education, internship classes

\section{Introduction}

Teacher personality, process-product, and expertise paradigm are three traditionally accepted areas in studies of instruction quality (Doyle, 1977). Currently, researchers mainly focused on expertise paradigm which studies teachers' knowledge and skills in their field. These researchers mostly used Shulman's (1986) classification of teachers' professional knowledge. This classification is primarily formed of three main dimensions named pedagogical knowledge, pedagogical content knowledge, and content knowledge. Geers, Alfs, and Hössle (2009) defined pedagogical content knowledge as making a scientific content comprehensible for student and preparing a matter for teaching. Many variables are pointed out in studies related to teaching quality in the literature. With meta-analysis, these variables grouped under related terms, therefore, properties of quality instruction can be formed and defined. Fundamental dimensions of quality instruction were defined as classroom management structuring instruction, clarity of content, feedback, practice and rehearsal, activation of cognition, and supporting classroom atmosphere (Brophy, 1999).

One of the important dimensions in this area is classroom management. In many studies, this concept is defined as generating and progressing a regular structure in the classroom. Effective classroom management is formed of integration of a defined body of rules in instruction process (Seidel, 2009). According to Helmke

\footnotetext{
*A similar version of this article was presented as a research paper at The 2nd International Instructional Technologies \& Teacher Education Symposium, 20-22 May, 2014, Afyonkarahisar, Turkey.

Güntay Taşçi, Ph.D., assistant professor, Department of Primary Education, Erzincan University.

Zafer Çepni, Ph.D., instructor, Educational Sciences Department, Hacettepe University.
} 
(2007), effective classroom management includes these three aspects: (a) establishing rules with the goal of prevention of disturbances and time loss; (b) time management for a successful teaching; and (c) effective to deal with disturbances. The learning climate which is closely related to classroom management is considered the main affective emphasis of interaction between teacher and student as well as learners' perception of the learning environment. Helmke (2007) regarded lesson structuredness the learning objectives of a class (lesson) as a criterion of a general presentation, summarizing or the structeredness of attention-controlled information and learn facilitating requests. Considering this, didactic structure and sequence of teaching requires rigorous course planning. Contextual clarity was defined as linguistically accurate, and comprehensible in addition scientifically approved and compatible with prior knowledge. Moreover, content clarity can be improved with using instructional strategies which can be seen as the use of different presentation formats (Lipowski, 2009; Helmke, 2007).

Turkish education system endeavors to raise its quality of instruction to international standards. The studies about instructional quality mainly emphasized teachers' qualifications. The emphasis on teacher qualifications also echoed in politics in Turkey. With collaborative efforts of Council of Higher Education (CoEH) and Ministry of National Education (MNE), curricula of education departments all over Turkey were reconstructed in 1997. Thus, more courses about professional teaching were added in pre-service teacher curriculum. Moreover, with two courses, namely, School Experience (Practicum) and Teaching Practice, teacher candidates gained experience in real school settings. Furthermore, MNE determined some standards for both pre- and in- service teachers. These standards were grouped in two aspects: (a) pedagogical teacher competencies (MNE, 2008); and (b) pedagogical content knowledge competencies (MNE, 2011). In these studies, content knowledge competencies were defined as knowledge, abilities, and attitudes that effective teaching requires from all teachers in their fields. All of these studies are based on the classification of pedagogical knowledge put forward by Shulman (1986), with related literature.

In this aspect, this research aimed to develop data collection tools for evaluation of school practice courses and for perceptions of teacher candidates regarding teacher competencies for effective teaching.

\section{Methods}

\section{Procedure}

Before writing items for Competency of Instruction Quality Scale (CIQS), the researchers reviewed a variety of studies (Brophy, 1999; Helmke, 2009; Seidel \& Shavelson, 2007) to determine international criteria to measure the quality of instruction. For each criterion, an item was generated. At the end of the item generation process, item pool consisting of 59 items was taken to a measurement expert and subject matter experts for receiving feedback. The experts suggested to cut down the number of items since some of the statements had very close meanings. To better understand which of the items needed to be dropped, the researchers run a pilot study then discarded some items according to pilot test results. Item generation for Evaluation of Practicum Scale (EPS) was launched analyzing Mayr's (1997) Intern Experience Scale. Some items were taken from this scale and others added considering the current application of practicum courses in Turkey. Participating teacher candidates responded to a total of 355 -point Likert-type items. Exploratory factor analysis (EFA) was used to explore possible sub-scales of the scales.

\section{Data Analysis}

Statistical Package for Social Sciences (SPSS) was used to analyze the data sets. First EFA was deployed 
to reveal any sub-scale. Unweighted least squares estimation method and Promax rotation were used in the factor analysis procedures. Scree plots have been examined in order to determine the number of the manifest latent factors in the data sets taken from the scales. Cronbach's $\alpha$ was used to calculate reliability of sub-scale scores.

\section{Participants}

The participants of this study were pre-service teachers from departments of primary and secondary education at two universities in Ankara and Erzincan, Turkey. As seen in Table 1, the participants were from seven different programs and mostly were males $(60 \%)$.

Table 1

Study Participants

\begin{tabular}{llrr}
\hline & & \multicolumn{2}{c}{$\%$} \\
\hline \multirow{2}{*}{ University } & Erzincan Univercity & 345 & 88.9 \\
& Hacettepe Univercity & 43 & 11.1 \\
\hline \multirow{3}{*}{ Program } & Primary School Teacher & 129 & 33.3 \\
& Elementary Math Teacher & 44 & 11.4 \\
& Social Sciences Teacher & 18 & 4.7 \\
& Science Teacher & 51 & 13.2 \\
& Biology Teacher & 4 & 1.1 \\
Class & Chemistry Teacher & 21 & 5.4 \\
& Math Teacher for Secondary Schools & 19 & 4.9 \\
\hline \multirow{2}{*}{ Gender } & 4-year & 289 & 74.7 \\
& 5-year & 43 & 11.1 \\
\hline
\end{tabular}

All participants took School Experience and Teaching Practice (Practicum) courses. They did practicum at primary and secondary level urban schools.

\section{Findings}

\section{Findings About EPS}

First of all, the items belonged to EPS was analyzed with EFA to determine any sub-scale. Eigenvalues and scree plot were reviewed and results can be seen in Figure 1 and Table 2.

As seen in Table 2, there were six factors which have eigenvalues 1 and above and these factors explained $58.11 \%$ of the total variance. However, the scree plot diagram shows only two factors, which explained $43.72 \%$ of the total variance. Based on these results, the researchers applied unweighted least square estimation method and Promax oblique rotation to data. Twenty-six items resulted in the first and nine items in the second factor. The items having factor loading below 0.20 were removed from the factors. After inspecting the reliability analysis of sub-scales, the items which lowered Cronbach's $\alpha$ value were not included the scale. At the end, a total of 18 items remained in the scale. Nine of these items constituted one sub-scale and the remaining nine items were in the other one. Scree plot and eigenvalues of the latest scale can be seen in Figure 2.

Table 3 constituted factor loadings of 18 items of EPS and none of the items factor loading were below 0.30 for the dimension that they belonged. As seen in Table 3, there were two factors which have eigenvalues 3 and above and these factors explained $49.09 \%$ of the total variance. 


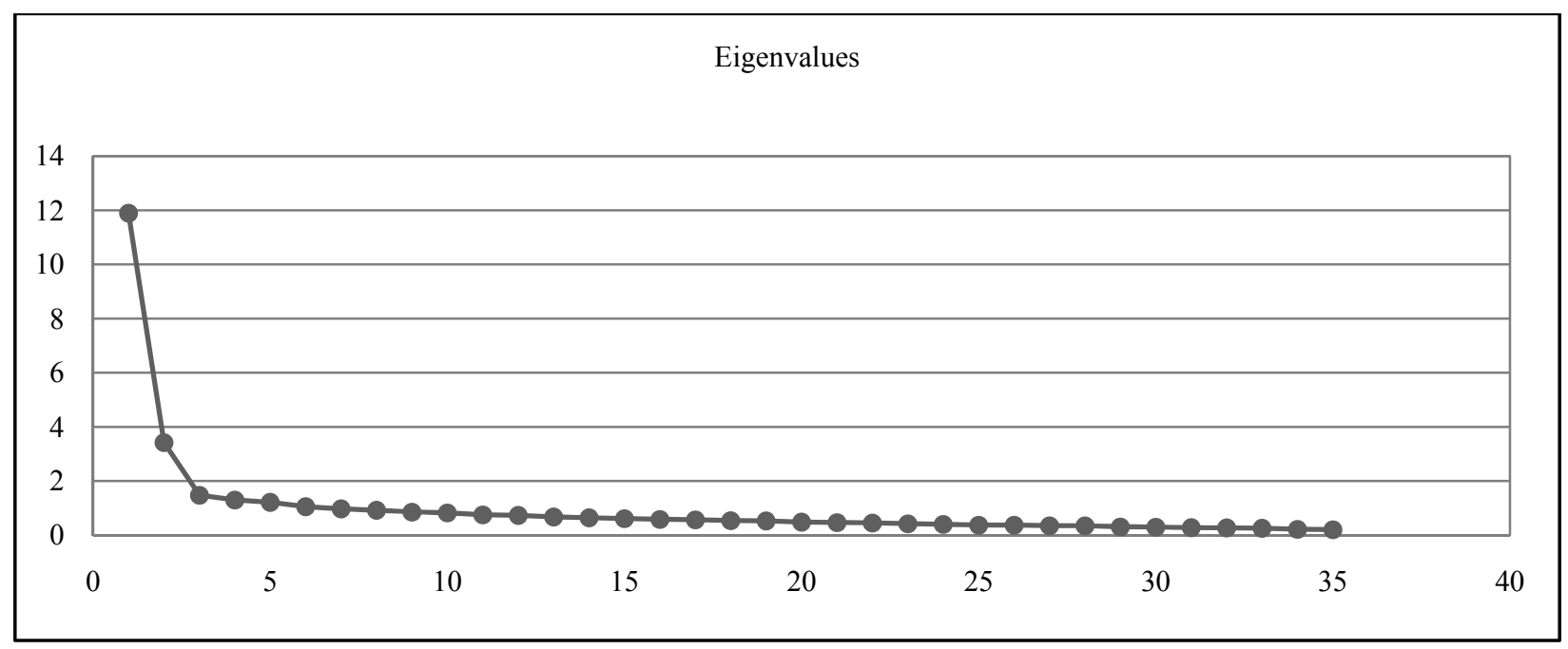

Figure 1. Scree plot of EPS.

Table 2

Eigenvalues and Explained Variances of EPS

\begin{tabular}{llll}
\hline Factor & Eigenvalue & Explained variance $(\%)$ & Total explained variance $(\%)$ \\
\hline 1 & 11.89 & 33.96 & 33.96 \\
2 & 3.42 & 9.76 & 43.72 \\
3 & 1.47 & 4.21 & 47.93 \\
4 & 1.30 & 3.70 & 51.63 \\
5 & 1.21 & 3.47 & 55.10 \\
6 & 1.05 & 3.01 & 58.11 \\
7 & 0.97 & 2.78 & 60.89 \\
8 & 0.92 & 2.63 & 63.53 \\
9 & 0.85 & 2.43 & 65.96 \\
10 & 0.82 & 2.36 & 68.32 \\
\hline
\end{tabular}

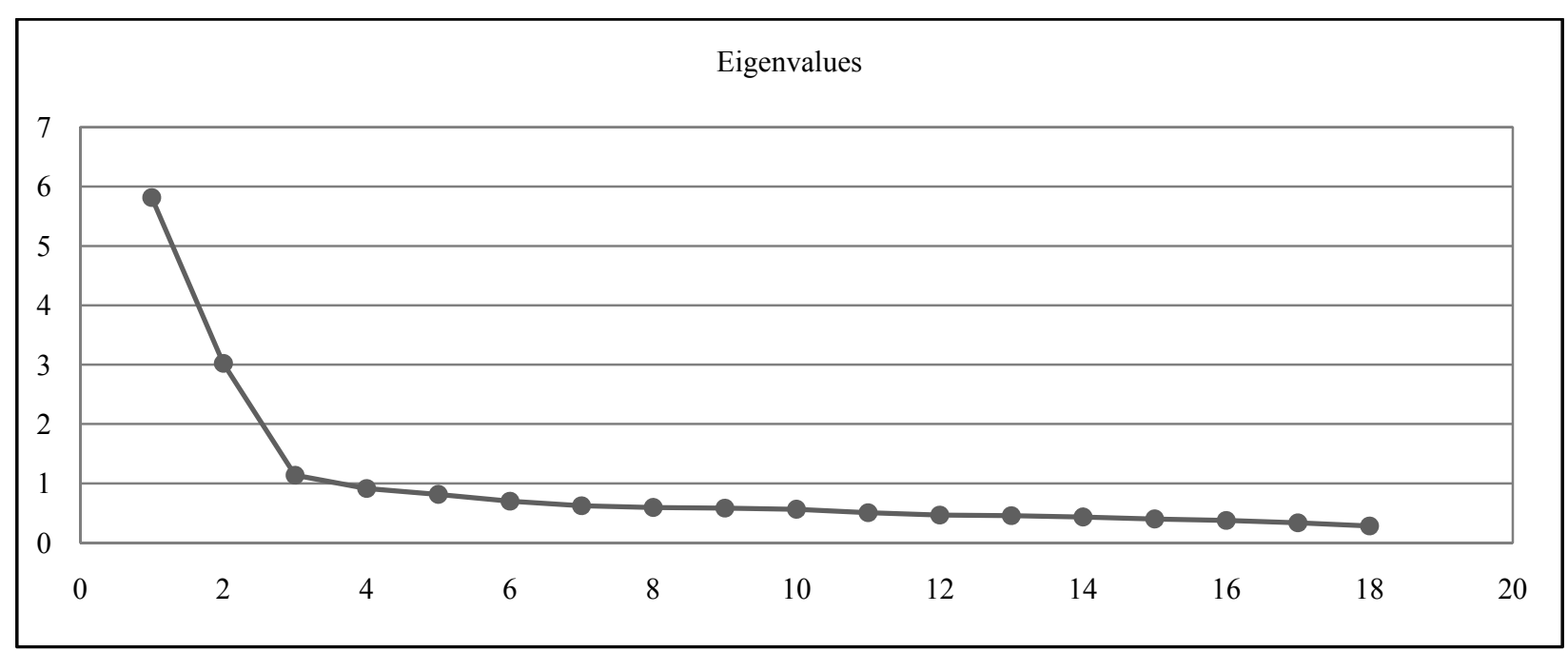

Figure 2. Scree plot for the final form of EPS.

One dimension of the scale was reviewed and statements in that group indicated positive (desirable) experiences, whereas other group of items in the second dimension included negative (undesirable) experiences. 
Thus, the first sub-scale was named as Positive (Desirable) School Experience [P(D)SE] and the second one was called Negative (Undesirable) School Experience [N(U)SE]. Cronbach's $\alpha$ value was 0.89 for P(D)SE and 0.83 for N(U)SE, which meant that sub-scale scores were highly reliable. Since the correlation coefficient between sub-scales showed a negative relationship (-0.30), sub-scale scores were used for evaluation (but not total scale scores). Authors do not advise to construct total scale scores for this instrument.

Table 3

Factor Loadings of EPS

\begin{tabular}{lccccc}
\hline \multirow{2}{*}{ Items } & \multicolumn{3}{c}{ Factor loadings } & \multicolumn{2}{c}{ Factor loadings } \\
\cline { 2 - 5 } & 1st factor & 2nd factor & & 1st factor & 2nd factor \\
\hline 8 & 0.73 & -0.29 & 20 & -0.27 & 0.73 \\
15 & 0.72 & -0.25 & 17 & -0.28 & 0.71 \\
26 & 0.72 & -0.30 & 31 & -0.19 & 0.64 \\
9 & 0.71 & -0.21 & 13 & -0.17 & 0.64 \\
19 & 0.71 & -0.28 & 21 & -0.23 & 0.63 \\
11 & 0.68 & -0.21 & 35 & -0.29 & 0.61 \\
3 & 0.66 & -0.18 & 29 & -0.24 & 0.61 \\
18 & 0.66 & -0.22 & 28 & -0.09 & 0.48 \\
25 & 0.61 & -0.23 & 6 & -0.14 & 0.39 \\
\hline Eigenvalue & 5.81 & 3.02 & & & \\
Explained variances (\%) & 32.30 & 16.79 & & & \\
\hline
\end{tabular}

\section{Findings About CIQS}

Factor analysis was applied on the data set which gathered through CIQS and results can be seen in Table 4 and scree plot graph (see Figure 3).

Table 4

Eigenvalues and Explained Variances of CIQS

\begin{tabular}{llll}
\hline Factor & Eigenvalue & Explained variance $(\%)$ & Total explained variance $(\%)$ \\
\hline 1 & 19.37 & 32.82 & 32.82 \\
2 & 2.42 & 4.10 & 36.92 \\
3 & 2.11 & 3.58 & 40.51 \\
4 & 2.03 & 3.45 & 43.95 \\
5 & 1.84 & 3.12 & 47.07 \\
6 & 1.61 & 2.74 & 49.80 \\
7 & 1.48 & 2.51 & 52.31 \\
8 & 1.33 & 2.26 & 54.57 \\
9 & 1.28 & 2.18 & 56.75 \\
10 & 1.22 & 2.07 & 58.82 \\
\hline
\end{tabular}

Both scree plot and eigenvalues indicated one dimension, explaining $32.82 \%$ of the total variance. Although the quality of instruction was explained with more than one category, this scale showed a single dimension. However, for the purpose of representing multiple category of instructional quality, the researchers selected items which had two highest factor loading scores from each dimension to constitute the scale. In addition, reliability analysis was conducted to finalize the scale. Factor loadings for the 19-item scale are presented in Table 5. As seen in Table 5, none of the factor loadings were below 0.40 , indicating the solid structure of the scale. Also, a 0.92 Cronbach's $\alpha$ value indicated that this scale is highly reliable 


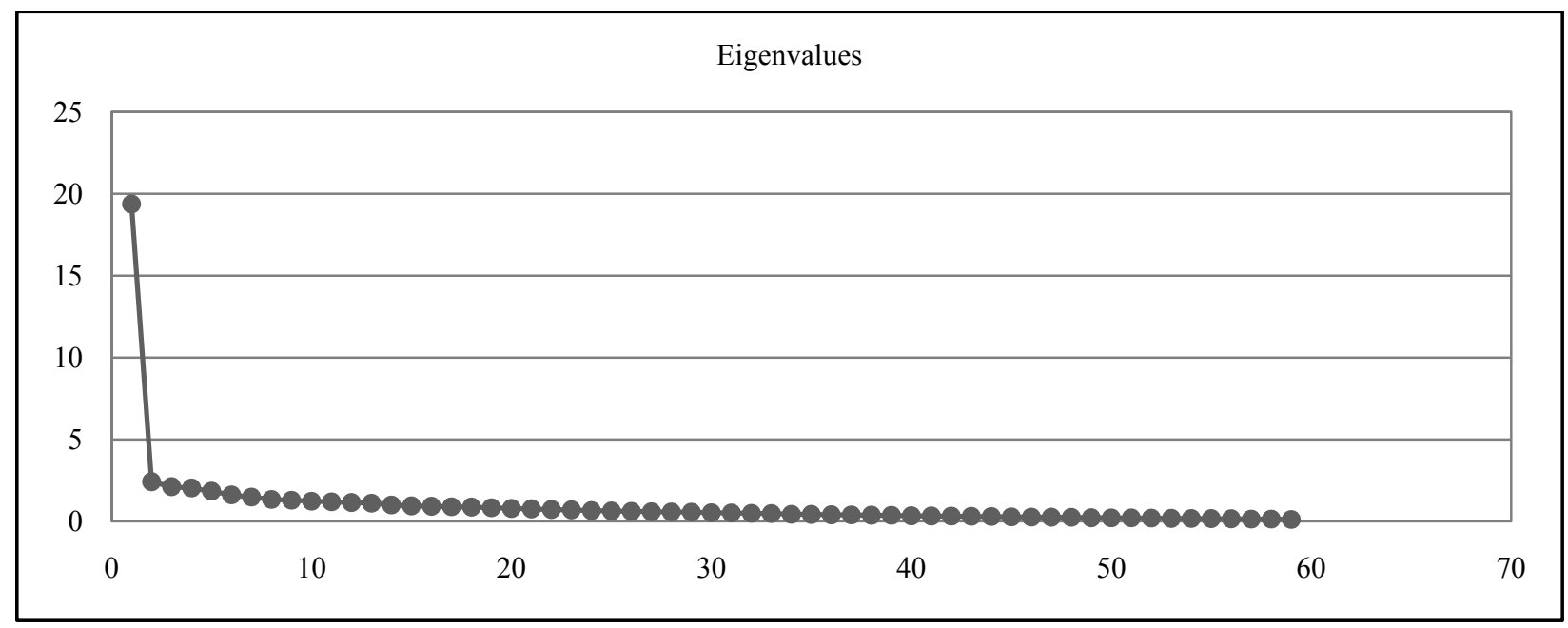

Figure 3. Scree plot of CIQS.

Table 5

Factor Loadings of CIQS

\begin{tabular}{llll}
\hline Items & Factor loadings & Items & Factor loadings \\
\hline 8 & 0.55 & 56 & 0.58 \\
13 & 0.66 & 57 & 0.57 \\
14 & 0.56 & 65 & 0.60 \\
15 & 0.62 & 66 & 0.63 \\
17 & 0.45 & 69 & 0.66 \\
26 & 0.64 & 70 & 0.65 \\
27 & 0.68 & 22 & 0.60 \\
31 & 0.69 & 48 & 0.65 \\
38 & 0.62 & 49 & 0.70 \\
39 & 0.66 & - & - \\
\hline
\end{tabular}

\section{Discussion and Conclusion}

Carrying out quality criteria that come into prominence with meta-analysis studies about teaching quality in classrooms and reflecting this to students will be possible with teacher qualifications. In this sense, the importance of teacher training is clearly seen in gaining qualifications. Therefore, it is necessary to measure and increase the perceptions of teacher candidates about their teaching quality criteria. One dimensional 19-item scale that is valid and reliable to serve this purpose was developed. Items of the scale include all of the teaching quality criteria that set by Brophy (1999) and Helmke (2007). Items are about different quality criteria, such as classroom management based on literature, positive classroom atmosphere, confusing teaching times, content clarity, and cognitive activation. However, factor analysis pointed out one dimension for all these sub-scales. Therefore, the scale composed of most powerful sub-scales that represent theoretical dimensions. CIQS was valid, reliable, and in accordance with measurement criteria and it represented theoretical structure of teaching quality. Good teaching or properties for effective teaching of teacher candidates were measured by either qualitative or quantitative research methods. Valid and reliable scales which were internationally accepted, based on strong theoretical basis, and allow teaching quality criteria were necessary in order to reach teaching quality goals of teacher training. For teacher candidates, School Experience and Teaching Practice courses were 
important applications that initiated by $\mathrm{CoEH}$ and provide them teaching experience and self-assessment method based on teaching quality criteria. EPS was a valid and reliable data collection tool with two dimensions and 18 items. EPS measures the efficiency of this process with negative and positive experiences in school practice.

\section{References}

Brophy, J. E. (1999). Teaching, educational practice series 1. Geneva: International Bureau of Education.

Doyle, W. (1977). Paradigms for research on teacher effectiveness. Review of Research in Education, 5, 163-198.

Geers, U., Alfs, N., \& Hössle, C. (2009). Fachdidaktisches wissen von lehrkräften zum thema "ökosysteme” sowie zum kompetenzbereich bewerten am beispiel "grüne gentechnik". In D. Krüger (Ed.), Erkenntnisweg biologiedidaktik (Cilt 11). Kassel: Universitätsdruckerei.

Helmke, A. (2007). Lernprozesse anregen und steuern-Was wissen wir über klarheit und structuriertheit? Padagogik, 6, 44-47.

Helmke, A. (2009). Unterrichtsqualität und lehrerprofessionalität: Diagnose, evaluation und verbesserung des unterrichts. Seelze: Kallmeyer in Verbindung mit Klett.

Lipowski, F. (2009). Unterricht. In E. Wild, \& J. Möller (Eds.), Pädagogische psychologie (pp. 135-148). Heidelberg: Springer.

Mayr, J. (1997). Die qualität der studienveranstaltungen an den pädagogischen akademien im urteil der studierenden. Zwischenergebnisse aus dem projekt "Evaluierung des Beratungsmaterials: Lehrer/in Werden?”. Linz: Pädagogische Akademie der Diözese.

Ministry of National Education (MNE). (2008). Öğretmenlik mesleği genel yeterlikleri. Retrieved from http://otmg.meb.gov.tr/ belgeler/ogretmen_yeterlikleri_kitabi/\%c3\%96\%c4\%9fretmen_yeterlikleri_adresindenalınmıştır

MNE. (2011). Özel alan yeterlikleri biyoloji. Retrieved March 22, 2013, from http://otmg.meb.gov.tr/yeterlikdos/b\%c4\%b0yoloj $\% \mathrm{c} 4 \% \mathrm{~b} 0 / \mathrm{b} \% \mathrm{c} 4 \%$ b0yoloj\%c4\%b0.pdf adresindenalınd 1

Seidel, T. (2009). Klassenführung. In E. Wild, \& J. Möller (Eds.), Pädagogische psychologie (pp. 135-148). Heidelberg: Springer.

Seidel, T., \& Shavelson, R. (2007). Teaching effectiveness research in the past decade: The role of theory and research design in disentangling meta-analysis results. Review of Educational Research, 77, 457-499.

Shulman, L. S. (1986). Who understand: Knowledge growth in teaching. Educational Researcher, 15(2), 4-14. 